\section{Adipose stromal vascular fraction and regenerative therapy in SSc: response to the article by Magalon et al}

We read with interest the report by Magalon et al, ${ }^{1}$ supporting the use of stromal vascular fraction (SVF) derived from adipose tissue, as an innovative autologous biotherapy for patients affected by systemic sclerosis (SSc). This disease is a complex multisystem disorder, characterised by microvascular damage, dysregulation of innate and adaptive immunity and generalised fibrosis in the skin and multiple organs, lacking a specific therapy. SSc is classified into two subsets: limited cutaneous (lcSSc), in which the skin fibrosis is limited to the extremities (hands, arms and face), and diffuse cutaneous (dcSSc), in which the skin fibrosis progresses more rapidly, affecting the trunk and extremities, frequently involving the internal organs. ${ }^{2}$ Due to this heterogeneity, in terms of extent, severity and rate of progression, it is still a matter of debate if both the subsets share a common pathogenic mechanism. At present, a growing body of evidence has been published concerning mesenchymal stem cells (MSCs) therapy for patients with SSc-the cell population larger represented in the SVF, in the last few years. In this work, the authors ${ }^{1}$ showed that the transcriptome profile of SVF, derived from patients with SSc, exhibited a profibrotic signature, without compromising the vascular repair capacity of SVF. In this context, we previously published data, confirmed also by other groups, showing a strong profibrotic signature in the MSCs, derived from patients with $\mathrm{dcSSc}^{2-6}$ and thus suggesting their involvement in the rapid evolution of fibrosis. Furthermore, the authors enrolled nine patients with dcSSc and 15 patients with lcSSc. Of note, the authors ${ }^{1}$ did not stratify the results between the two subsets and analysing the graphs of the paper, we may observe a large distribution of the data which partially impairs the results. Furthermore, the majority of the experiments were performed in very small number of patients (from 4 to 8 ) and without any explanation about how they were selected. Given the different profibrotic fate of patients with dcSSc and the significant profibrotic signature of MSCs derived from these patients, it should be important to compare the presence of possible different SVF effects, deriving from the two different subsets of the disease. Paradoxically, due to the MSCs profibrotic signature in SSc, it could be possible that the pathogenic milieu may force autologous cells to transdifferentiate to myofibroblasts, thus increasing the fibrotic burden. ${ }^{2-6}$ In fact, the transcriptomic analysis, in the study of Magalon $e t$ al $l^{1}$ confirmed the GDF15 gene overexpression which is strongly related to the fibrotic pathway. Further refinements in the understanding of SSc-SVF profile, together with targeted approaches to both SSc endothelial cells and pathological microenvironment, are needed to improve the regenerative approach of SSc.
Paola Di Benedetto $\odot,{ }^{1}$ Paola Cipriani, ${ }^{2}$ Piero Ruscitti, ${ }^{2}$ Vasiliki Liakouli, ${ }^{2}$ Roberto Giacomelli

${ }^{1}$ Clinical Pathology, Department of Biotechnological and Applied Clinical Sciences, University of L'Aquila, L'Aquila, Italy

${ }^{2}$ Rheumatology Unit, Department of Biotechnological and Applied Clinical Sciences, University of L'Aquila, L'Aquila, Italy

Correspondence to Dr Paola Di Benedetto, Department of Biotechnological and Applied Clinical Sciences, Clinical Pathology, University of L'Aquila, L'Aquila 67100, Italy; paola.dibenedetto1@univaq.it

Handling editor Josef S Smolen

Contributors PDB and RG wrote, analysed and conceived the study. PC, PR and $\mathrm{VL}$ analysed and conceived the study. All authors contributed to critical review and revision of the paper and approved the final version.

Funding The authors have not declared a specific grant for this research from any funding agency in the public, commercial or not-for-profit sectors.

Competing interests None declared.

Patient consent for publication Not required.

Provenance and peer review Not commissioned; internally peer reviewed.

(c) Author(s) (or their employer(s)) 2020. No commercial re-use. See rights and permissions. Published by BMJ.

\section{Check for updates}

To cite Di Benedetto P, Cipriani P, Ruscitti P, et al. Ann Rheum Dis 2020;79:e53.

Received 22 January 2019

Accepted 24 January 2019

Published Online First 2 February 2019

\section{(5) Linked}

http://dx.doi.org/10.1136/annrheumdis-2019-215132

Ann Rheum Dis 2020;79:e53. doi:10.1136/annrheumdis-2019-215113

\section{ORCID iD}

Paola Di Benedetto http://orcid.org/0000-0003-2927-8703

\section{REFERENCES}

1 Magalon J, Velier M, Simoncini S, et al. Molecular profile and proangiogenic activity of the adipose-derived stromal vascular fraction used as an autologous innovative medicinal product in patients with systemic sclerosis. Ann Rheum Dis 2019;78:391-8.

2 Gabrielli A, Avvedimento EV, Krieg T. Scleroderma. N Engl J Med 2009;360:1989-2003.

3 Hegner B, Schaub T, Catar R, et al. Intrinsic deregulation of vascular smooth muscle and myofibroblast differentiation in mesenchymal stromal cells from patients with systemic sclerosis. PLoS One 2016:11:e0153101.

4 Cipriani P, Marrelli A, Benedetto PD, et al. Scleroderma mesenchymal stem cells display a different phenotype from healthy controls; implications for regenerative medicine. Angiogenesis 2013;16:595-607.

5 Di Benedetto P, Liakouli V, Ruscitti P, et al. Blocking CD248 molecules in perivascular stromal cells of patients with systemic sclerosis strongly inhibits their differentiation toward myofibroblasts and proliferation: a new potential target for antifibrotic therapy. Arthritis Res Ther 2018;20.

6 Cipriani P, Di Benedetto P, Liakouli V, et al. Mesenchymal stem cells (MscS) from scleroderma patients (SSC) preserve their immunomodulatory properties although senescent and normally induce T regulatory cells (Tregs) with a functional phenotype: implications for cellular-based therapy. Clin Exp Immunol 2013;173:195-206. 